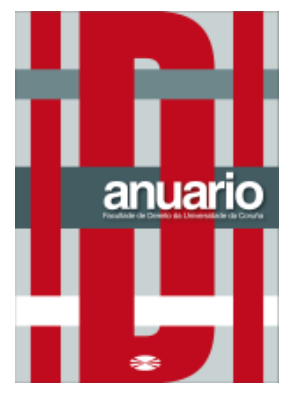

Anuario da Facultade de Dereito da Universidade da Coruña

Vol. 25 (2021), pp. 1-14

ISSNe: 2530-6324 || ISSN: 1138-039X

DOI: https://doi.org/10.17979/afdudc.2021.25.0.8794

\title{
LAS POSIBILIDADES DE RECLUTAMIENTO DE MANO DE OBRA A TRAVÉS DE EMPRESAS DE TRABAJO TEMPORAL EN LAS ADMINISTRACIONES PÚBLICAS
}

\section{THE POSSIBILITIES OF RECRUITING LABOR THROUGH TEMPORARY EMPLOYMENT AGENCIES IN PUBLIC ADMINISTRATIONS}

\author{
MARÍA JOSÉ BELINCHÓN ALENDE \\ Investigadora predoctoral \\ Universidad Complutense de Madrid \\ https://orcid.org/0000-0003-2413-3601
}

Recibido: $24 / 09 / 2021$

Aceptado: 22/11/2021

Resumen: A lo largo de la presente comunicación, se analizan las características especiales de la contratación laboral mediante empresas de trabajo temporal, así como la particular aplicación del contrato de puesta a disposición en el ámbito de las Administraciones Públicas. Todo ello, desde una perspectiva analítica en la que se evidencia la dificultad con la que se enfrenta la Administración a la hora de formalizar dichos contratos, dada su faceta de empleadora especial y a las consecuencias que dicha consideración supone ante la inexistencia de una regulación suficientemente clara e incapaz de resolver todos los problemas que subyacen tras la apertura de una vía para la contratación temporal mediante empresas de trabajo temporal.

Palabras clave: Administración Pública, empresas de trabajo temporal, contratación laboral.

Abstract: Throughout this communication, the special characteristics of employment contracts through temporary work agencies are being analyzed, and the particular application of the contract availability in the field of public administration. All this, from an 
analytical perspective where the difficulties faced by the Administration when it comes to formalizing these contracts are made evident, given its facet as a special employer, the consequences in consideration of the absence of a sufficiently clear regulation, causing an incapacity in resolving all the problems underlying the opening of a temporary recruitment route through temporary work agencies.

Keywords: Public Administration, temporary work agencies, laboral contracting.

Sumario: I. EL MARCO NORMATIVO DE LAS ETT. II. LOS CONTRATOS DE PUESTA A DISPOSICIÓN. III. POSIBILIDADES Y DIFICULTADES DEL USO DE ETT EN LAS AAPP. IV. LA REACCIÓN LEGAL Y ADMINISTRATIVA FRENTE A LOS EFECTOS DE LA CESIÓN ILEGAL. BIBLIOGRAFÍA.

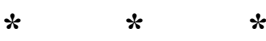

\section{EL MARCO NORMATIVO DE LAS ETT}

La Directiva 2008/104/CE, del Parlamento Europeo y del Consejo, de 19 noviembre de 2008, reguladora de las empresas de trabajo temporal, en consonancia con el Convenio sobre las agencias de empleo privadas de 1997, $\mathrm{n}^{\circ} 181$ de la OIT, ratificado por España en 1999, mejoró las condiciones de los trabajadores temporales ampliando su protección en el ámbito de las ETT. Sobre todo, en lo que corresponde a la necesaria igualdad de trato entre trabajadores contratados mediante ETT y el resto de trabajadores pertenecientes a las llamadas empresas usuarias.

Por su parte, la Directiva 2008/104/CE, permitió la posibilidad de formalizar contratos de puesta a disposición en el seno de las Administraciones Públicas, al reconocer que únicamente los estados miembros podían excluir o restringir la contratación mediante ETT por cuestiones de interés general, por exigencias en materia de salud y seguridad en el trabajo, o bien por la necesidad de garantizar el buen funcionamiento del mercado de trabajo y evitar posibles abusos. En consecuencia, debía entenderse que las Administraciones Públicas quedaban incluidas dentro del ámbito de actuación de las ETT.

A la vista de esta nueva situación, España se vio obligada a modificar la regulación preexistente y adecuarla a los nuevos requerimientos procedentes de la Unión Europea. Este cambio vino de la mano del artículo 17 de la Ley 35/2010, de 17 de septiembre, de medidas urgentes para la reforma del mercado de trabajo, mediante el cual, se incluyó la Disposición Adicional Cuarta ${ }^{1}$ de la Ley 14/1994, de 1 de junio, reguladora de las

\footnotetext{
${ }^{1}$ Artículo 17 de la Ley 35/2010, de 17 de septiembre, de medidas urgentes para la reforma del mercado de trabajo, incorporó la Disposición Adicional Cuarta de la Ley 14/1994, de 1 de junio, por la que se regulan las Empresas de Trabajo Temporal, mediante la que se suprimían, a partir del 1 de abril de 2011, todas las limitaciones o prohibiciones hasta entonces vigentes para la celebración de contratos de puesta a disposición por las empresas de trabajo temporal, incluida la recogida en la Disposición Adicional Quinta de la Ley 30/2007, de 30 de octubre, de contratos del sector público, con la única excepción de lo establecido en la Ley. A partir de esa fecha, las limitaciones o prohibiciones que pudieran ser impuestas, sólo serían válidas cuando
} 
Empresas de Trabajo Temporal, que permitió a las Administraciones Públicas formalizar contratos temporales a través de ETT.

También contribuyó a este cambio el Real Decreto Ley 3/2012, de 10 de febrero de medidas urgentes para la reforma del mercado laboral, permitiendo a las ETT operar como agencias de colocación con ánimo de lucro, siempre que presentaran una declaración de responsable, a fin de acreditar el cumplimiento de los requisitos establecidos en la Ley de Empleo y su normativa de desarrollo. De esta manera, las ETT podían colaborar con los Servicios Públicos de Empleo en ámbito la intermediación laboral entre trabajadores y empleadores.

Así pues, es necesario recordar que el artículo 1 del Estatuto de los Trabajadores, considera empresarios a aquellas personas físicas o jurídicas que reciban la prestación de servicios de personas contratadas por empresas de trabajo temporal legalmente constituidas, para ser cedidas a empresas usuarias. A su vez, el artículo 1 de la Ley 14/1994, de 1 de junio, de Empresas de Trabajo Temporal, define las ETT como empresas cuya actividad fundamental consiste en poner a disposición de otra empresa usuaria, con carácter temporal, trabajadores por ella contratados. Para ello, la ETT correspondiente deberá obtener una autorización administrativa, inscribirse en el registro de Empresas de Trabajo Temporal, y constituir una garantía financiera. Adicionalmente, tal y como exigen los artículos 2 a 5 de la Ley 14/1994, de 1 de junio, de Empresas de Trabajo Temporal, una vez suscrito el contrato de puesta a disposición, estas empresas deberán informar a la autoridad laboral competente, entre otros extremos, del número y características de los contratos de puesta a disposición celebrados.

Actualmente, la Ley 9/2017, de 8 de noviembre, de Contratos del Sector Público, por la que se transponen al ordenamiento jurídico español las Directivas del Parlamento Europeo y del Consejo 2014/23/UE y 2014/24/UE, de 26 de febrero de 2014, permite este tipo de contratación en el entorno de las Administraciones Públicas. A este respecto, es necesario tener en cuenta que tal y como establece la Audiencia Nacional en su sentencia de 7 de marzo de 2019 (rec. 16/2019), la Administración, en su papel de empresa usuaria, debe responsabilizarse de cuestiones como la cuantificación de las percepciones finales del trabajador, la parte proporcional correspondiente al descanso semanal, las pagas extraordinarias, los festivos a disfrutar por los trabajadores, y las vacaciones.

Por todo ello, a día de hoy existe la posibilidad de que una empresa usuaria, que puede ser cualquier Administración Pública, requiera los servicios de las ETT para cubrir determinadas necesidades de naturaleza temporal, como es la contratación de personal cualificado o los trabajos de carácter urgente, siembre bajo los términos previstos en la Ley.

\section{LOS CONTRATOS DE PUESTA A DISPOSICIÓN}

fuesen justificadas por razones de interés general y relativas a la protección de los trabajadores cedidos por empresas de trabajo temporal, a fin de garantizar el buen funcionamiento del mercado de trabajo y a evitar posibles abusos. 
Los contratos de puesta a disposición se recogen en la Ley 14/1994, de 1 de junio, por la que se regulan las Empresas de Trabajo Temporal, en el Real Decreto 417/2015, de 29 de mayo, por el que se aprueba el Reglamento de las empresas de trabajo temporal, así como en el Estatuto de los Trabajadores y demás Leyes de aplicación. Tal y como establece el artículo 6 de la Ley de Empresas de Trabajo Temporal, estos contratos son los que se suscriben entre la ETT y una empresa usuaria, con el objeto de llevar a cabo una cesión de trabajadores por parte de la ETT que prestarán servicios en la empresa usuaria.

Por lo tanto, es posible suscribir contratos de puesta a disposición bajo las mismas condiciones, términos y requisitos que tendría la empresa usuaria, si fuese ella misma quien formalizara contratos de duración determinada, siempre de conformidad con lo dispuesto en el Estatuto de los Trabajadores. Así pues, los contratos suscritos en el seno de un contrato de puesta a disposición deberán incluir los requerimientos exigidos para los contratos laborales temporales, como la identificación de las partes contratantes, la identificación de la empresa usuaria, la definición del objeto del contrato de puesta a disposición, los detalles sobre el contenido de la prestación laboral, el lugar y horario de trabajo, junto con la información detallada sobre los riesgos profesionales del puesto de trabajo a desempeñar.

La principal característica diferenciadora entre el contrato de puesta a disposición y el resto de contratos laborales, reside en que el contrato de puesta a disposición tiene una naturaleza mercantil, debido a que se formaliza entre la ETT y la empresa usuaria. Requiere, además, la formalización de un segundo contrato de naturaleza laboral entre el trabajador y la ETT contratante. Por otra parte, es necesario apuntar que la cesión de trabajadores está prohibida a excepción de contratos de puesta a disposición gestionados por ETT.

Dada su particularidad, los contratos de puesta a disposición cuentan con unos férreos límites que les otorgan unas características especiales, como la necesidad de que su jornada laboral será establecida por la empresa cesionaria con una duración mínima de cuatro horas, la necesidad de que su remuneración sea fijada de acuerdo con la categoría profesional del trabajador, o bien, la necesidad de que se especifique el convenio de aplicación de la empresa contratante. Por su parte, los trabajadores percibirán una retribución íntegra que deberá incluir los festivos, las partes proporcionales de pagas extraordinarias y las vacaciones, calculadas mediante unidades de tiempo.

Ciertamente, las características de la relación entre la empresa usuaria y el trabajador cedido suponen una complejidad singular, al no existir la vinculación legal suscitada entre las partes que proporciona el contrato de trabajo. A pesar de ello, corresponden a la empresa usuaria cuestiones como el ejercicio del poder de dirección ${ }^{2}$ sobre los trabajadores cedidos, la potestad disciplinaria, la obligación de informar a los trabajadores sobre la política de seguridad y salud en el centro de trabajo, la responsabilidad subsidiaria en los supuestos de contratación ilegal, así como en las obligaciones salariales y de seguridad social.

\footnotetext{
${ }^{2}$ Artículo 6 de la Ley 14/1994, de 1 de junio, de Empresas de Trabajo Temporal.
} 
Por otra parte, el artículo 8 de la Ley 14/1994, recoge las prohibiciones de contratación mediante ETT en los casos de sustitución de trabajadores por huelga, cuando se trata de especialmente peligrosos para la seguridad y salud ${ }^{3}$, o bien, si en los doce meses inmediatamente anteriores a la contratación la empresa haya amortizado los puestos de trabajo que se pretenden cubrir por despido improcedente, extinción por voluntad del trabajador, despido colectivo o extinción del contrato por causas objetivas. Tampoco es posible contratar a trabajadores para cederlos a otras empresas de trabajo temporal.

En cuanto a la necesaria temporalidad de los contratos de puesta a disposición, señalar que son de aplicación los artículos 11 y 15 del Estatuto de los Trabajadores, así como lo establecido en sus disposiciones de desarrollo. Por ende, cuando los contratos se hayan suscrito por tiempo determinado en los mismos términos que recoge el Estatuto de los Trabajadores, existirá el derecho a recibir una indemnización a la finalización de los mismos, equivalente a la parte proporcional de la cantidad que resultaría de abonar doce días de salario por cada año de servicio, o bien, la cantidad que determine la normativa específica que sea de aplicación, a excepción de los contratos de interinidad y los contratos formativos.

En este sentido, el Tribunal Superior de Justicia del País Vasco, mediante su sentencia de fecha 6 de junio de 2017 (rec. 1338/2017), reconoció una indemnización de veinte días por año trabajado a la finalización de un contrato por obra y servicio suscrito mediante ETT. Este tribunal entendió que era de aplicación la doctrina del Tribunal de Justicia de la Unión Europea de 14 de septiembre de 2016 (asunto C-596/14, de Diego Porras), donde se establecía, mediante el artículo 5.1 de la Directiva 2008/104/CE, que las condiciones de los trabajadores contratados por ETT debían ser, al menos, iguales a las que les corresponderían si hubiesen sido contratado directamente por la empresa usuaria para ocupar el mismo puesto. Tal consideración impidió un trato desfavorable, como sería la indemnización de doce días a la finalización del contrato, dado que al trabajador se le había reconocido la situación de indefinido.

\section{POSIBILIDADES Y DIFICULTADES DEL USO DE ETT EN LAS AAPP}

La problemática que suscita el reconocimiento de un trabajador como indefinido a consecuencia del incumplimiento de los límites legales definidos para los contratos de puesta a disposición, incide de manera más profunda cuando se produce en el ámbito del empleo público, dadas las particularidades y límites propios de la Administración en su faceta de empleadora especial ${ }^{4}$.

\footnotetext{
${ }^{3}$ Siendo aquellos trabajos que impliquen la exposición a radiaciones ionizantes en zonas controladas, según el Real Decreto 783/2001, de 6 de julio; trabajos que impliquen la exposición a agentes cancerígenos, mutagénicos o tóxicos para la reproducción, de primera y segunda categoría, según el Real Decreto 363/1995; de 10 de marzo y trabajos que impliquen la exposición a agentes biológicos de los grupos 3 y 4 , según el Real Decreto 664/1997, de 2 de mayo.

${ }^{4}$ Vid. PALOMAR OLMEDA, A. "La incidencia de las nuevas reformas legislativas en la definición del Estatuto de los Funcionarios Públicos", Revista de Administración Pública 381, Núm. 134. Mayo-agosto 1994, Pág. 415: La incidencia de la reforma de la Ley 30/1984 en el ámbito laboral es, a nuestro juicio, una de las medidas que contiene la Ley 22/1993 que ofrece una mayor complejidad, ya que supone dotar a la Administración, en cuanto empresario, de un status que se niega al resto de los empresarios. El
} 
Por ello, en el entorno de la Administración Pública, el uso de los contratos de puesta a disposición no ha tenido buena acogida por parte de la doctrina, al entender, ya en su momento, que la Disposición Adicional Cuarta de la Ley 14/1994, no afectaba a la, hoy derogada, Ley de Contratos en el Sector Público por ser esta una norma especial dirigida a encajar la legislación relativa a las empresas de trabajo temporal en el ámbito de la Administración. Así pues, se consideraba que la reforma de la Ley general dejaba incólume la especial. Salvando esta cuestión aclarada a día de hoy, el principal problema residía en que "tal liberalización resultaba contraria a los principios constitucionales que rigen el acceso a la función pública" 5 , algo que podría ampliar el riesgo de que los trabajadores cedidos a las Administraciones Públicas mediante ETT, pudieran conseguir un puesto dentro del empleo público sin pasar por procesos regulados.

Si bien es cierto que los contratos de puesta a disposición no suponen el acceso directo a un empleo público, ni los trabajadores cedidos pueden ser considerados empleados públicos ${ }^{6}$, tal previsión se ha ido materializando, con cierta frecuencia, debido a que las diferentes Administraciones no han cumplido estrictamente lo establecido en la Ley, bien por las particularidades propias de los contratos de puesta a disposición, bien por la dificultad añadida con la que se han encontrado a la hora de ejercer su especial papel de empleador que lleva aparejada la necesidad de encajar el Derecho Laboral con el Derecho Administrativo.

Esta difícil situación ha dejado sin resolver cuestiones como la aplicabilidad del ya indicado artículo 7.2 de la Ley 14/1994, que reconoce como indefinido al trabajador que continúa prestando servicios en la empresa usuaria, una vez finalizado el plazo de duración del contrato de puesta a disposición. En esta misma situación se encuentran los trabajadores cedidos ilegalmente, al ser contratados para cubrir puestos de naturaleza estructural desoyendo los requerimientos que la propia norma expresa en cuanto a las especiales condiciones que deben darse para cubrir puestos de trabajo mediante ETT, en el entorno de las Administraciones Públicas, equiparando así sus funciones a las de unos empleados públicos laborales que se han visto obligados a superar determinados procesos de acceso al empleo público en condiciones de igualdad, mérito y capacidad.

\footnotetext{
planteamiento correcto una vez superada la concepción teórica que pretendía que el derecho laboral fuese la alternativa al régimen público sería la negación del fenómeno y probablemente haría inútil la continuación de la presente exposición, ya que el marco legal para el personal laboral en la Administración Pública es realmente estrecho y marcadamente restrictivo. Sin embargo, la evolución que en los últimos años está sufriendo el sector público, en su conjunto, nos lleva a indicar que el proceso laborizador lejos de estar arrumbado aparece ahora con mayor fuerza, aunque por una vía diferente, la del sometimiento al derecho privado de la actuación administrativa.

${ }^{5}$ PÉREZ DE LOS COBOS ORIHUEL, F. Diario La ley, No 7588, sección tributaria, 14 marzo 2011.

${ }^{6}$ Ver en este sentido PÉREZ DE LOS COBOS ORIHUEL, F. Diario La ley, № 7588, sección tributaria, 14 marzo 2011: ...creemos, de un presupuesto falso: el de que a través de un contrato de puesta a disposición se accede a la función pública. Nada más lejos de la realidad, el trabajador cedido es siempre un trabajador de la empresa de trabajo temporal y, por tanto, no accede a la función pública. Siendo esto así, huelga cualquier referencia, creo, a los principios constitucionales del art. 103.3 CE para la selección de trabajadores por la ETT. Serán los criterios constitucionales y legales que garantizan la pulcritud en la contratación pública los que deban respetarse cuando la Administración contrate los servicios de una empresa de trabajo temporal.
} 
Ante las diferentes situaciones irregulares detectadas en el colectivo de trabajadores contratados por ETT, la Jurisprudencia no tardó mucho en pronunciarse mediante sentencias como la del Tribunal Supremo, de 4 de julio de 2006 (rec.1077/2005) y de 28 de septiembre de 2006 (rec. 2691/2005), entre otras ${ }^{7}$, que reconocieron a estos trabajadores la condición indefinidos no fijo. De esta manera, trabajadores que inicialmente habían sido contratado a través de ETT, se convertían en empleados públicos que ocuparían plazas dentro de la Administración correspondiente, hasta la cobertura definitiva de las mismas mediante procesos regulados de acceso al empleo público.

En este escenario, el Real Decreto Ley 20/2012, de 13 de julio, de medidas para garantizar la estabilidad presupuestaria y de fomento de la competitividad, en su Disposición Adicional Primera, reconocía la necesidad de que fueran las propias Administraciones Públicas quienes elaboraran, en sus respectivos ámbitos competenciales, instrucciones pertinentes para la correcta ejecución de las contrataciones de determinados servicios externos que, por sus características especiales podían ser contratados mediante ETT o subcontratados, con el fin de establecer unos criterios evasivos de actos que pudieran ser considerados como determinantes de la existencia de una relación laboral, sin perjuicio del ejercicio de la potestad de dirección de los trabajos que la Ley de Contratos del Sector Público les otorga.

Sobre esta cuestión se asentaba la Resolución de 27 de octubre de 2010, aprobada por la Comisión Mixta para las Relaciones con el Tribunal de Cuentas, dada la necesidad de evitar el riesgo de que los trabajadores de las empresas de servicios contratadas por la Administración se convirtieran en personal laboral indefinido, en virtud de sentencias judiciales dictadas como consecuencia de las condiciones en las que se desarrollaba la actividad contratada. Para ello, mediante esta Resolución se intentaron definir mecanismos encaminados mejorar la contratación de servicios externos mediante ETT, a través del Diálogo Social y la Mesa General de Negociación, de acuerdo con la legislación vigente y los servicios y funciones susceptibles de ser externalizados para suplir la carencia de personal permanente, a fin de orientar a las Administraciones Públicas y así evitar el riesgo de incurrir en irregularidades en su gestión de los contratos de puesta a disposición.

De manera que, en la Resolución de 27 de octubre de 2010, se hacía referencia a la Disposición Adicional Decimoquinta ${ }^{8}$ de la Ley 35/2010, de 17 de septiembre, de medidas urgentes para la reforma del mercado de trabajo, así como a la Disposición Adicional Decimoquinta del Estatuto de los Trabajadores ${ }^{9}$, incidiendo en la importancia de fijar con la

\footnotetext{
${ }^{7}$ Sentencias del TS, de 3 de noviembre de 2008 (rec. 3883/2007 y 1889/2007); de 19 de febrero de 2009 (rec. 2748/2007).

${ }^{8}$ Donde se establecía un plazo de 6 meses para que el Gobierno aprobara un proyecto de ley de reforma del texto refundido de la Ley de Procedimiento Laboral, donde debía contemplarse la atribución al orden jurisdiccional social, de manera que, mediante la Ley 3/2012, de 6 de julio, de medidas urgentes para la reforma del mercado laboral, se recogió tal requerimiento que consta en el artículo 2 de la Ley 36/2011, de 10 de octubre, reguladora de la jurisdicción social.

${ }^{9}$ Que recoge la aplicación de los límites de duración del contrato por obra o servicio determinados y encadenamiento de contratos en las Administraciones Públicas. De conformidad con el artículo 15.1.a) y 15.5 del TRET, y en materia de duración máxima del contrato por obra o servicio determinados y límites al encadenamiento de contratos. Con la particularidad de que lo dispuesto en el artículo 15.1.a), en materia de duración máxima del contrato por obra o servicio determinados, no será de aplicación a los contratos
} 
máxima precisión las prestaciones a desarrollar dentro de los pliegos administrativos, a fin de vigilar su cumplimiento y asegurar la ausencia de desviaciones del cumplimiento de los servicios previamente definidos en los pliegos, durante la ejecución de los correspondientes contratos, a fin de poder evitar que el personal procedente de contratos de puesta a disposición pudiera, en algún momento, pasar a formar parte del colectivo de empleados públicos.

Por tanto, se evidenciaba la necesidad de dictar instrucciones dentro de cada ámbito competencial para la correcta ejecución de los servicios externos contratados por medio de ETT, con el fin de clasificar la relación suscitada mediante los contratos de puesta a disposición entre los respectivos gestores de la Administración y el personal de la empresa contratada, con el objeto de evitar actos que pudieran ser considerados como determinantes en el reconocimiento de una relación laboral subyacente. Todo ello sin perjuicio de las facultades que la legislación de contratos del sector público reconoce al órgano de contratación. Se contempló, además, la conveniencia de exigir responsabilidades en el caso de incumplimiento de la legislación vigente, a fin de evitar adscripciones definitivas a los puestos de trabajo reconocidas en sentencias que juzguen posibles irregularidades en la contratación.

A pesar de todo ello, la Resolución de 27 de octubre de 2010, no profundizó en la definición de las medidas a tomar por las diferentes Administraciones Públicas a la hora de contratar trabajadores por medio de ETT. En realidad, se limitó a unificar unas medidas generales y diseminadas por diferentes leyes, pero sin llegar a establecer un nivel de detalle suficiente sobre las precauciones de necesaria aplicación en estos casos.

A modo de ejemplo, determinada normativa autonómica como la Instrucción 1/2011, de 27 de octubre de la Junta Consultiva de Contratación Administrativa de la Generalidad de Cataluña, ponía en evidencia las carencias existentes en cuanto a la definición de los criterios funcionales de aplicación de este nuevo régimen, por parte del legislador y recordaba la necesidad de observancia de los límites que las diferentes leyes establecen, como son el respeto a los principios constitucionales de igualdad mérito y capacidad para el acceso al empleo público, y las tareas reservadas a funcionarios públicos ${ }^{10}$ contenidas en normas con rango de ley, tanto estatales como autonómicas. Es importante destacar que se habla de tareas y no de puestos de trabajo.

celebrados por las Administraciones Públicas y sus organismos públicos vinculados o dependientes, ni a las modalidades particulares de contrato de trabajo contempladas en la Ley Orgánica 6/2001, de 21 de diciembre, de Universidades o en cualesquiera otras normas con rango de ley, cuando estén vinculados a un proyecto específico de investigación o de inversión de duración superior a tres años. Tampoco lo dispuesto en el apartado 5 del referido artículo 15, en lo relativo a las modalidades particulares de contrato de trabajo contempladas en la Ley Orgánica 6/2001, de 21 de diciembre, de Universidades o en cualesquiera otras normas con rango de ley.

${ }^{10}$ En este punto es necesario recordar que el artículo 9.2 del Estatuto Básico del Empleado Público, delimita las funciones que únicamente podrán llevar a cabo los funcionarios públicos, siendo estas aquellas que impliquen la participación directa o indirecta en el ejercicio de potestades públicas o en la salvaguardia de los intereses generales del Estado y de las Administraciones Públicas, en los términos que en la Ley de desarrollo de cada Administración Pública establezca. 
Al igual que la Resolución de 27 de octubre de 2010, la Instrucción 1/2011 puso en evidencia la necesidad de contemplar lo regulado en el artículo 7.2 de la Ley de Empresas de Trabajo Temporal, donde se determinan los plazos de duración de los contratos de puesta a disposición, así como la posibilidad de que dichos contratos se conviertan en indefinidos. De ahí que la Instrucción 1/2011 incidiera en la necesidad de que los pliegos de cláusulas administrativas particulares, tanto en los contratos de servicios como en los celebrados mediante ETT, incluyeran, con la máxima precisión, las prestaciones que debían de llevarse a cabo dentro de los contratos de puesta a disposición. Añadiendo a lo anterior los medios de control a utilizar, a fin de asegurar la inexistencia de deviaciones sobre los acuerdos pactados y el cumplimiento de los plazos fijados, como mecanismo evasivo del reconocimiento de trabajadores indefinidos no fijos por parte de los tribunales.

Como novedad, tanto la Recomendación 1/2012, de 4 de diciembre, en relación con los trabajadores de las empresas en los contratos de servicios, de la Consejería de Hacienda y Administración Pública de la Junta de Andalucía, como la Instrucción 1/2011, de 27 de octubre de la Junta Consultiva de Contratación Administrativa de la Generalidad de Cataluña, además de reproducir lo ya indicado en las Instrucciones del Tribunal de Cuentas, incluyeron, de manera muy acertada, ejemplos de redacción de cláusulas para incluirlas en los Pliegos Administrativos, así como indicaciones sobre la necesidad de que fuesen aportados determinados documentos relativos a la planificación y organización como herramientas para evitar la posibilidad de conversión de un trabajador cedido en un trabajador indefinido no fijo.

También se aconsejaba solicitar a la empresa contratada un estudio organizativo del servicio a prestar, que debía incluir tanto la metodología de los trabajos a desarrollar como los manuales de procedimiento para la prestación del servicio, con la descripción de la forma en la que tales funciones debían ser realizarlas, destacando el ejercicio de la potestad directiva sobre del personal por parte de la empresa cesionaria, así como la necesidad de sujeción del contrato a cláusulas donde se debía aclarar que la dirección y gestión del contrato era potestad del contratista como responsable de la organización del servicio prestado y de la calidad técnica de los trabajos, siempre de conformidad con los términos del artículo 305.1 de la Ley de Contratos del Sector Público.

Para el cumplimiento de tales requerimientos se aconsejaba la existencia de estructura jerarquizada dentro la empresa dotada de personal responsable de impartir órdenes y criterios para la realización del trabajo, así la necesidad de constatar que los poderes de verificación y control del contrato le correspondían a la Administración contratante, quien debería abstenerse de ejercer control, dirección u organización alguno sobre el personal de la empresa contratista. Por ese motivo, se evidenciaba la necesidad de reflejar en los pliegos de contratación, en los casos en los que los trabajadores contratados por la empresa contratista debían desempeñar su labor en las dependencias de la Administración, que los medios materiales se debían aportar tanto por la empresa contratista como por la propia Administración contratante, con el requerimiento de que el contratista debía disponer de un seguro de responsabilidad civil sobre los posibles daños en los bienes públicos. 
A pesar de todo ello, los trabajadores provenientes de contratos de puesta a disposición en el entorno de las Administraciones Públicas, siguen siendo reconocidos como personal indefinido no fijo, mediante sentencias como la del Tribunal Superior de Justicia de Galicia, de 28 de abril de 2017 (rec.126/2017), y la de 27 de febrero de 2017 (rec. 4396/2017) del mismo Tribunal, entre otras ${ }^{11}$. Incluso, tras la entrada en vigor del Real Decreto 417/2015, de 29 de mayo, por el que se aprueba el Reglamento de las empresas de trabajo temporal, que se limitó a abordar esta materia desde una perspectiva general, centrando sus novedades en la autorización administrativa para que las ETT pudieran desarrollar su actividad, además de la implantación de la Administración Electrónica en todo el procedimiento administrativo relacionado con las ETT, si afrontar específicamente la problemática del uso de ETT en el entorno público.

\section{LA REACCIÓN LEGAL Y ADMINISTRATIVA FRENTE A LOS EFECTOS DE LA CESIÓN ILEGAL}

El complicado encaje entre Derecho Administrativo y Derecho Laboral ha dificultado la labor de la Administración como empleadora, a la hora de cumplir los requerimientos legales para la contratación de personal mediante ETT. Esta cuestión ha provocado que, de manera frecuente, eclosiones un sustrato de relaciones laborales entre los trabajadores puestos a disposición y la Administración contratante, precipitando la existencia de la llamada cesión ilegal de estos trabajadores, que supone el incumpliendo la normativa laboral y administrativa. De ahí que la Ley de Contratos del Sector Público intentara poner límites legales a este hecho, incluyendo mediante el artículo 301.4 la advertencia de que, una vez extinguidos los contratos de servicios, en ningún caso se produciría la consolidación de las personas que hubiesen realizado los trabajos objeto del contrato como personal adscrito a la Administración contratante.

A pesar de ello, la Ley de Contratos del Sector Público no ha podido evitar per se el reconocimiento de la existencia de este tipo de relaciones laborales entre la Administración y el personal puesto a disposición. En contrapartida, tampoco se han definido mecanismos para impedir la vulneración de los límites determinados en las leyes de aplicación para este tipo de contratos.

El artículo 43 del Estatuto de los Trabajadores, reconoce como fijos los contratos donde se ha producido una cesión ilegal de trabajadores, es decir, los contratos cuyo objeto se limita a una mera puesta a disposición de los trabajadores de la empresa cedente a la empresa cesionaria no gestionados mediante ETT, o bien, cuando la empresa cedente carezca de una actividad u organización propia y estable, no cuente con los medios necesarios para el desarrollo de su actividad, o no ejerza funciones inherentes a su condición de empresario. En estos casos, el Estatuto de los Trabajadores otorga al trabajador el derecho de elegir ser fijo en la empresa cedente o cesionaria, que podría ser una Administración Pública.

\footnotetext{
${ }^{11}$ Sentencias del TSJ de Andalucía, de 15 febrero 2017 (rec. 1909/2016), del TSJ de Extremadura, de 11 abril 2017 (rec. 633/2016), y del TSJ de Madrid, de 29 marzo 2017 (rec. 1005/2016).
} 
En el ámbito del empleo público, el legislador ha convenido que estos contratos no deben ser una vía para alterar el régimen general de la contratación temporal, sino, únicamente, un instrumento para trasladar la temporalidad del ámbito de contratación de la empresa usuaria a la empresa de trabajo temporal ${ }^{12}$. A pesar de ello, es frecuente la existencia de cesión ilegal de trabajadores cuando los contratos de puesta a disposición son utilizados para responder necesidades permanentes y estructurales de mano de obra, o bien en los casos en los que se formalizan contratos para llevar a cabo unas funciones determinadas, cuando la realidad es que se desarrollan otras completamente distintas.

La cesión ilegal de trabajadores no supone el único incumplimiento por el que los contratos temporales pueden recalificarse como contratos indefinidos. El artículo 15 del Estatuto de los Trabajadores, reconoce como indefinidos aquellos contratos temporales celebrados en fraude de ley, y recalifica como fijos los contratos de obra o servicio cuya duración haya superado el límite legal de tres años, ampliable hasta doce meses más por convenio colectivo, también aquellos que se alarguen durante un plazo superior a veinticuatro meses en un periodo de treinta meses, con o sin solución de continuidad, para el mismo o diferente puesto de trabajo, con la misma empresa o grupo de empresas mediante dos o más contratos temporales, sea directamente o a través de su puesta a disposición por empresas de trabajo temporal, con las mismas o diferentes modalidades contractuales.

Estas normas tuitivas vienen a reconocer la existencia de fraude de ley, cuando el objeto es distinto a la finalidad de la norma y contrario al ordenamiento jurídico, de ahí que la aplicación automática del carácter indefinido o fijo del contrato, se recoge de manera indistinta en el Estatuto Básico del Empleado Público, cuestión que lleva a pensar que el legislador utiliza la palabra indefinido como sinónimo de fijeza ${ }^{13}$. Tal concesión no ha tenido fácil encaje, debido a la naturaleza del artículo 103 de la Constitución Española, que eleva a constitucionales los principios de igualdad, mérito y capacidad, en el acceso al empleo público.

Esta contradictoria situación suscitada entre las diferentes leyes de aplicación, precipitó una forzosa respuesta aclarativa proveniente la jurisprudencia que, ante las demandas de los trabajadores, se vio obligada a matizar las exigencias del Estatuto de los Trabajadores reconociendo que la legislación laboral es aplicable a los empleados públicos con determinadas particularidades derivadas de sus leyes específicas.

Conviene, en este punto, hacer una breve reflexión sobre la evolución de los diferentes pronunciamientos jurisprudenciales que, sobre esta cuestión, se han ido sucediendo a lo largo de los años, para dar respuesta al incumplimiento de la Administración en lo que respecta a la contratación temporal.

\footnotetext{
${ }^{12}$ Sentencia del TSJ de Madrid, de 30 de septiembre de 2009 (rec. 15/2019).

${ }^{13}$ RECUERDA GIRELA M.A. y FERNÁNDEZ DEPUECH, L. "Los contratos administrativos que encubren relaciones laborales o tienen por objeto funciones reservadas al personal funcionario", Revista Andaluza de la Administración Pública, núm. 83, Sevilla 2012, págs. 51-92.
} 
Tras un largo devenir de cambiantes sentencias, a través de las cuales el Tribunal Supremo ha ido madurando su posición, que en un inicio se situaba al lado del principio pro operario $^{14}$, para adoptar posteriormente un lugar más cercano a los intereses de las Administraciones Públicas. Puede observarse, por tanto, la existencia de una marcada evolución que partió de una postura inicial más alejada de los intereses de los trabajadores, en pos de los de la Administración, para posicionarse más tarde en un ecuador de pronunciamientos que intentaban establecer soluciones equitativas para ambas partes, hasta que, finalmente, se llegó a la creación de una doctrina más unificadora y no alejada de la necesaria aplicación de los principios constitucionales de acceso al empleo público, ni del sometimiento de las Administraciones públicas a los sistemas o procedimientos de contratación reglados.

Esta nueva doctrina se inició con la sentencia del Tribunal Supremo, de 7 de octubre de 1996 (rec. 3307/1995) ${ }^{15}$, creadora de una nueva modalidad de contratos laborales en la Administración Pública, a los que se les otorgó el nombre de contratos indefinidos no fijos. Tales contratos se crearon bajo una teoría fundamentada en el necesario resarcimiento de los trabajadores sometidos a una situación fraudulenta y su particular situación dentro del empleo público, por la que no podían ser equiparados a los trabajadores laborales fijos al servicio de la Administración, dada la necesaria aplicación de sistemas adecuados de ponderación de los principios de igualdad mérito y capacidad en el acceso al empleo público.

Por consiguiente, la contratación laboral en las Administraciones Públicas, al margen del procedimiento legalmente establecido, calificó como trabajadores vinculados a la Administración mediante un contrato laboral por tiempo indefinido, a los trabajadores incorporados al servicio público tras una sentencia judicial. De tal manera que se diferenciaron de aquellos trabajadores que habían superado procedimientos de selección reglados para acceder a puestos laborales fijos. Esta cuestión supuso una circunstancia jurídico-laboral que respondía al contenido del aforismo certus an, incertus quando ${ }^{16}$, como una circunstancia intermedia entre los trabajadores temporales y fijos ${ }^{17}$, que se alargaría hasta la cobertura definitiva de la plaza que habían ocupado.

\footnotetext{
${ }^{14}$ Tras la entrada en vigor de la Ley de Medidas para la Reforma del Empleo Público, esta doctrina jurídica sufrió un giro, entre muchas otra, las sentencias del TS de 9 de octubre de 1985, 24 de abril de 1986, 21 de febrero de 1987, 30 de enero de 1988, 27 de febrero de 1989 o 20 de febrero de 1990, marcaron un giro hacia la concepción de que el carácter indefinido de los contratos laborales temporales celebrados en supuestos de fraude de ley, así como en los casos en que la sanción se fundamentará en dicha consideración, chocaba con los principios constitucionales de igualdad, mérito, capacidad y publicidad en el acceso al empleo público, y chocaba también con el procedimiento de selección previsto en la Ley 30/84, que impedían la aplicación de la legislación laboral.

${ }^{15}$ Esta posición jurisprudencial fue reiterada y posteriormente mantenida a través de los pronunciamientos judiciales de sentencias como las del TS, de 30 de diciembre de 1996 (rec. 637/1996), 11 de marzo de 1997 (rec. 3940/1996) o 7 de julio de 1997 (rec. 3971/1996), y de los TSJ de Cataluña 10 de marzo de 1997 (AS 1997, 1833) y País Vasco 21 de octubre de 1997 (AS 1997, 3521) y 4 de noviembre de 1997 (AS 1997, 4482), entre muchas otras.

${ }^{16}$ Sentencia del TSJ de Cataluña, de 10 de marzo de 1997 (AS 1997, 1833).

${ }^{17}$ Sentencia TSJ del País Vasco, de 4 de noviembre de 1997 (AS 1997, 4482).
} 
Desde entonces, la doctrina jurídica ha venido identificando a los trabajadores indefinidos no fijos como aquel colectivo que accede a la estabilidad en el empleo público por medio de una vía espuria ${ }^{18}$, a consecuencia del incumplimiento de la Administración y sin que haya mediado un proceso de acceso al empleo público basado en la concurrencia libre y la pugna igualitaria entre los aspirantes. Por ello, su naturaleza será temporal hasta la cobertura definitiva de las plazas, calificándose esta particular vía de acceso al empleo público como una sutil pero ambigua distinción ${ }^{19}$.

En este contexto, la Ley 43/2006, de 29 de diciembre, para la mejora del crecimiento y del empleo, apoyó la creación jurisprudencial del reconocimiento de los trabajadores como indefinidos no fijos, mediante la introducción de la Disposición Adicional Decimoquinta del Estatuto de los Trabajadores, donde se reconocía que los efectos del encadenamiento de contratos suscitados en el ámbito de las Administraciones Públicas no podía equivaler al reconocimiento de la condición de fijo, pero si supondría que estos trabajadores continuarían desempeñando el puesto que venían ocupando hasta su cobertura definitiva, momento en el que se produciría la extinción de la relación laboral, siempre que no hubiesen accedido a sus plazas tras superar el correspondiente proceso selectivo.

Más tarde, el Estatuto Básico del Empleado Público de 2007, reconocía la figura del trabajador indefinido en su artículo 11, distinguiéndolo del personal laboral fijo y temporal. A día de hoy, incluso tras aprobarse el Estatuto Básico del Empleado Público de 2015, el régimen jurídico de los trabajadores indefinidos no fijos aún no ha sido regulado.

En el ámbito de los contratos de puesta a disposición, cuando la entidad condenada a aceptar a los trabajadores cedidos es una Administración Pública, la jurisprudencia ha determinado que los trabajadores no adquirirán la condición de fijos, sino la de indefinidos no fijos ${ }^{20}$. Sin perjuicio de alguna sentencia como la del Tribunal Superior de Justicia de Baleares, de 17 de marzo de 2020 (rec. 326/2019), donde se reconoce la situación de fijo y no la de indefinido no fijo a un trabajador, al entender que la recalificación de los contratos como indefinidos no fijos, conculca la doctrina contenida en la sentencia del tribunal de Justicia de la Unión Europea, de 13 de junio de 2017 (asunto c-317/18 Correira MoreiraPortimão). De manera que, ante una situación de cesión ilegal, este Tribunal manifiesta que las consecuencias establecidas en el artículo 43 del Estatuto de los Trabajadores no pueden verse afectadas por el hecho de que la empresa cesionaria sea una Administración pública, y que la actividad desarrollada por esta fuera finalmente internalizada por el Ayuntamiento.

\section{BIBLIOGRAFÍA}

RECUERDA GIRELA, M. A. y FERNÁNDEZ DEPUECH, L. "Los contratos administrativos que encubren relaciones laborales o tienen por objeto funciones reservadas

\footnotetext{
${ }^{18}$ SÁNCHEZ MORÓN, M. Derecho de la Función Pública, edic. 13ª , edit. Tecnos, Madrid 2020, pág. 99.

${ }^{19}$ Sentencias del Tribunal Supremo de 20 de enero de 1998 (rec. 317/1997) y 21 de enero de 1998 (rec. 315/1997).

${ }^{20}$ STS 11 de noviembre 2003 (rec. 3898/2002), a la que se siguen otras como las de 11 de diciembre de 2002 (rec. 639/2002); 19 de noviembre 2002 (rec. 909/2002); y 17 de septiembre 2002 (rec. 3047/2001).
} 
al personal funcionario", Revista Andaluza de la Administración Pública, núm. 83, Sevilla 2012.

PÉREZ DE LOS COBOS ORIHUEL, F. "La contratación de trabajadores a través de empresas de trabajo temporal en las Administraciones Públicas", Diario La ley, N 7588 , sección tributaria.

PALOMAR OLMEDA, A. "La incidencia de las nuevas reformas legislativas en la definición del Estatuto de los Funcionarios Públicos", Revista de Administración Pública 381, núm. 134. Mayo-agosto 1994.

SÁNCHEZ MORÓN, M. Derecho de la Función Pública, edic. 13ª, edit. Tecnos, Madrid 2020. 